English Language and Linguistics, 25.4: 851-871. (C) The Author(s), 2021. Published by Cambridge University Press. This is an Open Access article, distributed under the terms of the Creative Commons Attribution licence (http://creativecommons.org/licenses/by/4.0/), which permits unrestricted re-use, distribution, and reproduction in any medium, provided the original work is properly cited.

doi: $10.1017 / \mathrm{S} 1360674320000428$

\title{
Emergent labial stops in English
}

\author{
A NNA W O J T Ś \\ University of Warsaw \\ (Received 15 July 2019; revised 10 August 2020)
}

\begin{abstract}
The lexicon of English contains a number of words which developed emergent stops, mostly $p, b, t, d$. Some of these words have functioned as variants of forms without such stops (cf. OE endleofan $\sim$ enlefan or gandra $\sim$ ganra) but in most cases they prevail in Present-day English, as exemplified by OE nimol $>$ ModE nimble, OE cemtig $>$ ModE empty.

The present study examines the process of labial stop epenthesis from the perspective of diachrony and diatopy. I searched for the words containing emergent labial stops in the texts collected in historical English corpora to identify their uses with and without parasitic consonants. This made it possible to establish a precise chronology of the process, which was at work from Old to Modern English, and the context in which such stops appeared.
\end{abstract}

Keywords: consonant epenthesis, labial stops, corpus study, historical phonology, emergent consonants

\section{Introduction}

In the history of English, labial stops have been affected by a number of phonological changes, the most conspicuous of which have been deletion and epenthesis. The former applied predominantly to the voiced stop /b/ in homorganic clusters, e.g. lamb or plumber, the latter introduced both voiced and voiceless plosives, e.g. stumble (Middle English (ME) stomle) and empty (Old English (OE) cemtig). Emergent labial stops are found in several different contexts and seem to have developed at various moments of the history of English with the earliest examples attested already in the Old English period. And although the issue is mentioned in a number of publications, it has never been discussed in detail: the available accounts provide only selected examples and typically ignore items which contained an emergent labial stop only occasionally and temporarily.

Labial stop epenthesis is dealt with in numerous publications on historical phonology, typically in the parts devoted to the particular periods of the history of English. For Old English, Hogg (1992: 298) claims that epenthesis is '[m] uch less frequent than the simplification of consonant clusters by deletion' and that ' $[\mathrm{t}]$ he most regular examples of epenthesis occur medially between a nasal or, less commonly still, the strident $/ \mathrm{s} /$ and a sonorant consonant, that is, a liquid or a nasal'. His examples include broembel 'bramble', cumble 'wound', hymblicae 'hemlock' and symble 'always'. Hogg adds a footnote about the word cemptig 'empty' as an example of epenthesis between a nasal and an obstruent. Mincoff exemplifies labial stop epenthesis with brcem(b)las 'brambles' 
for the $m l$ cluster and timbrian 'build' for $m r$, adding that '[s]uch epenthesis becomes more frequent in ME' (Mincoff 1972: 100). It was then, he continues, that a ' $p$ was inserted between $m$ and dentals in $e m(p) t y . ., \operatorname{drem}(p) t e$ GE. "dreamt", nem( $p)$ nen "name", ampte "ant" (1972: 244) and 'an epenthetic $b$ between $m-l, m-r$ ' was added mainly in the South and Midlands, the examples being thim(b)el, shambles, nimble, slumber, thumbes (<pum(b)en) (1972: 245). Epenthesis is also mentioned in the sections devoted to Modern English changes, where it is attributed to the elimination of unstressed vowels and further promoted by its earlier appearance in inflected forms, e.g. thimble, nimble, shambles and embers (Mincoff 1972: 340). Regardless of all the above-listed Old English examples, Luick rather assigns labial epenthesis to Middle and Modern English, e.g. 'Aus $m$ entwickelte sich spätmittelenglisch und frühneuenglisch $m b$ ' (Luick 1940: 1039), although he admits the earlier attestation of thumb: 'Dagegen ist $m b$ in thumb schon im letzten Teil der Chronik zum Jahre 1137 belegt (bumbes) ${ }^{1}$ (Luick 1940: 1041). Note that the above-mentioned accounts focus on the interconsonantal context for the epenthesis, disregarding their emergence in a word-final position, a process which is rather rare (Minkova 2014: 48). In English, the most common excrescent consonants are dental stops ${ }^{2}$ (e.g. in sound, against, amongst), while the final voiced labial stop which was occasionally attached to the words is 'merely graphic' (OED, crumb).

Stop epenthesis has been explained in various ways. In a syllable-based approach, it is believed to improve the syllabic structure of a word. For many languages, epenthetic consonants provide a missing onset; ${ }^{3}$ in English, however, they are assumed to 'improve the overall shape of the syllable' so that the words 'have filled codas' and 'the least sonorous of all consonants', i.e. stops, in onsets, e.g. bra.mel, spi.nel, pu.nor, which after epenthesis are resyllabified as bram.ble, spin.dle, thun.der (Minkova 2014: 48). The process has also been handled in terms of articulatory gestures, with stops inserted between nasals and sonorants because the pronunciation of such a cluster 'requires a delicate timing in the adjustment of articulatory gestures' (Hock \& Joseph 1996: 132) with different valves open for the two subsequent sounds. During the movement from nasal to sonorant, there is 'a transitional state' and 'when the valve that was closed for the initial sound ... is opened, a stop burst will be produced' (Ohala 1997: 85), which is a kind of 'transitional sound' (Wełna 1978: 140) typically referred to as epenthetic stop. Those approaches are further discussed in section 7 , once the data have been presented and the exact contexts for epenthesis established. That section also clarifies the use of the label 'emergent', rather than 'epenthetic', in the title of the present article.

1 'In Late Middle English and Early Modern English $m b$ developed from $m$... However, $m b$ in thumb is documented already in the last part of the Chronicle for the year 1137 (bumbes)' [translation mine].

2 Although the term typically used nowadays for $t$ and $d$ is 'alveolar', I follow the convention of historical linguistic texts referring to those stops as 'dental'.

${ }^{3}$ In Optimality Theory a syllable without an onset is treated as marked, according to the long-noticed general preference for CV syllables (see e.g. Jakobson 1929). To ensure the presence of the onsets, the ONSET constraint (Syllables must have onsets) was introduced (see Payne 1981 or Prince \& Smolensky 2004). Note, however, that this does not account for the interconsonantal epenthesis present in English, as explained in detail by Czaplicki 2010. 
Table 1. First occurrences of words with epenthetic b (from Wetna 2005: 325-6)

\begin{tabular}{lll}
\hline \hline Item affected & \multicolumn{1}{c}{ Earliest form with $b$} & Date \\
\hline bramble & bræmbel, -e- (Ælfric) & $c .1000^{4}$ \\
thumb & pumbes (Pet. Chronicle) & 1137 \\
tumble & tumbled (CM) & $a .1300$ \\
stumble & stumble (Brunne) & 1303 \\
slumber & slumberde (P.Pl) & 1362 \\
rumble & romble (Barbour) & 1384 \\
ember & eymbre (Pr.Parv) & $c .1440$ \\
thimble & thymbyl (Pr.Parv) & $c .1440$ \\
mumble & mumbled (Alph.T.) & 1440 \\
crumb & crombys (Alph.T) & $c .1450$ \\
shamble & sheambles & 1477 \\
fimble & femble & 1484 \\
nimble & nymbyll & 1496 \\
limb & limbe & 2 nd half of 16th cent. \\
\hline
\end{tabular}

The most complete list of items affected by labial stop epenthesis is found in Welna's article (2005), although it is limited to the words with the letter $b$ (see table 1). The words are arranged in chronological order according to their first occurrence with the stop. The dating follows that of the Oxford English Dictionary $(O E D)$ and the Middle English Dictionary $(M E D)$. As the table shows, the list of words includes only those in which the epenthetic stop prevails in Modern English disregarding items that appeared with such a consonant only occasionally and temporarily. Note that in all items, epenthetic $b$ appeared after the labial nasal $m$.

The remainder of this article is structured as follows: section 2 presents the aims and methods used in the study; sections 3 and 4 contain the analysis of the data concerning epenthetic $p$ and $b$, respectively; section 5 focuses on dialectal distribution of labial epenthesis, while section 6 lists potential exceptions to the process. Possible explanations for labial epenthesis are discussed in detail in section 7. The article ends with conclusions, which are listed in section 8 .

\section{Aims and methods}

This study aims at completing the list of words which have had emergent labial stops during the history of English, expanding it to cover also those items that had a labial stop for a certain time but which lack the consonant in Present-day English (PDE). I verify the dating of forms with a labial stop provided in the historical dictionaries, using data from the text corpora such as Dictionary of Old English Corpus (DOEC), A

\footnotetext{
${ }^{4}$ In dates, $c$. is used for circa 'around', $a$. for ante 'before'.
} 
Linguistic Atlas of Early Middle English (LAEME), Corpus of Middle English Prose and Verse (CMEPV) and Early English Books Online (EEBO) with references to Eighteenth Century Collections Online (ECCO). For the verification of examples historical dictionaries were used such as An Anglo-Saxon Dictionary (ASD), Dictionary of Old English (DOE), Middle English Dictionary (MED), Oxford English Dictionary (OED) and Dictionary of the Scots Language (DSL). Furthermore, the analysis of data from the corpora may be expected to provide a more detailed attestation record than the dictionaries. This might result in more accurate datings of the last attestations of forms without the emergent labial stop and the frequency of both types of forms, i.e. with and without the stop. Yet another goal of the study is to demonstrate if epenthetic labial stops had a tendency to appear in specific areas or whether it was a general phenomenon. I also aim to suggest the most convincing explanation for labial stop epenthesis.

It needs to be clarified that since the study is devoted to historical data, the discussion of epenthesis is based on attested spellings, i.e. it is assumed that the presence of a letter representing the labial stop $(<\mathrm{p}>$ or $\langle\mathrm{b}\rangle)$ in a word reflected its pronunciation. Naturally, the spelling cannot be treated as completely reliable evidence of past pronunciation(s), but in view of the lack of other types of evidence as well as numerous examples of originally epenthetic labials still present in the phonology of the language, both in spelling and pronunciation, it seems a reasonable hypothesis (see section 4.1 for a situation where this is not the case, however). Note that whenever the study mentions labial stops in italics $(p, b)$, it refers to the spelling and, consequently, the expected pronunciation of the sound.

\section{Epenthetic $p$}

Both labial stops have been subject to permanent and occasional/temporary epenthesis. In the examined data, voiceless $p$ was permanently inserted in only two English common words, i.e. empty and glimpse. The other items affected were place names ending in -hampton, e.g. Northampton, Southampton; -hamstead, e.g. Dunhampstead, Finchampstead; and -ton, e.g. Bempton, Compton. An emergent voiceless stop has also appeared in Hampshire. The list of words which have been attested with emergent $p$ only occasionally (and temporarily) includes aemette (PDE ant), antemn (PDE anthem), column, count, dreamt, hymn, nemnan (PDE name), summoner and the place name Medeshamsted. In all examples, as might be expected, the stop appeared after $m$.

\subsection{Permanent epenthesis}

The typical OE form of the adjective empty was cemtig(e). This form accounts for 87 out of 91 tokens for the word in DOEC. The remaining four occurrences are with epenthetic $p$. These form are attested in Ælfric's texts: Saint Euphrosyne (emptige), homily Feria VI (cemptig) and the second letter to Wulfstan (cemptige), as well as in Psalms from MS 
Cotton Vitellius E.XVIII (cemptig). Thus, the written evidence suggests that the epenthesis can be dated to the end of the Old English period. Interestingly, none of the related words, i.e. the verb (ge)aemtigian and the noun cemta, betrays any tendency towards the addition of a stop.

In Early Middle English, forms with epenthetic $p$ are still in the minority, as shown in data from LAEME, which contains six such forms as compared to ten without the stop. But they gain frequency in the period so that the ratio of the two types of forms is reversed in the CMEPV, where empty (also spelt with initial $<\mathrm{a}>$ ) is encountered 68 times while emti/amti occurs merely 23 times. Interestingly, the forms with and without the stop are occasionally found within the same texts (1a) or in different manuscripts of one source (1b).

(1) (a) and pe slak[e] skyn tremblep vpon myn emty body ... wip a lijfly colour and wip swiche vigoure and strenkep pat it ne my3t[e] not be emptid. (Chaucer, Boece, British Library, MS Additional 10340, pp. 4-5)

(b) Pat were ampty In pine londe · ware pou wost bi penche **. [were ampty] amty were B; ampti were $\alpha$; ampty were $\beta \gamma . . .$.$] (Robert of Gloucester, Chronicle,$ 1. 944)

In Early Modern English (EModE), forms without $p$ become very rare: there are only 67 occurrences in EEBO (vs more than 40,000 instances of the $p$-form). In the $O E D$ the most recent quotation with emty is that from Brevint's Saul and Samuel at Endor, dated to 1674, but EEBO provides later uses, such as in Allestree's Clito and Harrington's The Oceana, both published in 1700. With no examples found in ECCO, these two seem to be the last attestations of the $p$-less form in English.

Curiously, the data also contain forms in which the dental $t$ is missing rather than the labial $p$, as in (2).

(2) (a) ... yt is to say yt he be not to full ne to empy to full then wolde the humours louse ... (1506?, Here begynneth a lytell treatyse called the gouernall, unnumbered)

(b) ... Oh man, thou art a vessel, but a ful vessell, put out \& empy that which is within thee ... (1618, La Primaudaye, The French academie ..., p. 881)

With only two such examples, however, it is impossible to determine whether such a form ever reflected the pronunciation or was simply the result of a misprint.

In empty, the context for epenthesis is: between the labial nasal and the dental stop. However, as noticed by Ohala (1997: 84-5), the context of nasal + fricative could also lead to the development of epenthetic stops (cf. e.g. the pronunciation of warmth or the name Thomson). Such a context is encountered in glimpse. As its first attestation, the $O E D$ provides the line from Chaucer's The Merchant's Tale, which contains the form glimsing (with the variants glemesyng and glynsyng (MED)). The OED suggests that the verb could go back to an unattested OE item * glimsian (from West Germanic * glimmisôjan). The first verbal form with $p$ is recorded by the $O E D$ in 1592 with an earlier record of the noun glimpsing, dated to 1563. This instance is also the earliest one in the examined data and one of the two attestations of the word in the CMEPV. 
The word gains frequency in Early Modern English, when the form with $p$ becomes around 15 times more common than that without the stop (158 vs 2,391 occurrences in EEBO, respectively). Rare as it is, glimse continues to appear until the end of the seventeenth century, the last attestation coming from 1699 in EEBO (the last record in the $O E D$ is from 1663).

The data that I considered also contain several other items which are recorded in historical texts both with and without $p$, which might suggest that they, too, were affected by epenthesis. To those belong words such as e.g. peremptory and tempt(ation). Such words, however, are disregarded in the present study since they already had $p$ when they entered the language, as the first attestations, given here in (3), show.

(3) (a) ... have from pe King lettres peremptorie of request to pe said Duc such as pe cas requireth. (Proceedings and Ordinances of Privy Council 1443 (1835) V. 277)

(b) ... pet te deouel tempti us ouer pet he sið wel pet we mahen polien. I pe temptatiun he haueð iset to pe feond a mearke. (Ancrene Riwle, MS Corpus Christi College 402, c.1230(?a.1200), p. 118, 11. 9-10)

The fact that the labial stop in these words may not be original can be deduced only on examining their etymology. Peremptory comes from an Anglo-Norman word which had the variants with and without the stop, i.e. peremptorie/paremptorie as well as peremtorie/ perantorie (OED, peremptory), while tempt was borrowed from French (tempter) coming from Latin temptāre/temtāre (OED, tempt). Thus, it is possible that the words that entered English derived from the variants containing the stop, which would mean that no epenthesis took place during the history of English.

Note that, similarly to empty, the two types of forms are also occasionally attested within the same text for peremptory (4a) and temptation (4b), showing that they could be used interchangeably.

(4) (a) And when this choice after Deliberation is peremtory and full, it's called Resolution ... And your Resolution must be Absolute and peremptory,... (Baxter, Directions and perswasions to a sound conversion ..., 1658, pp. 449-56)

(b) ... pat pou be myn help \& counfort in al my temtacioun, ... 3it, lord swete Ihesu, pis liff is ful of temptaciouns and enemyes, ... (Rolle, Meditations on the Passion, University Library MS Additional 3042, pp. 93-4)

Epenthetic $p$ is also encountered in several English place names, i.e. particularly those with the compound element -hamton, which in OE functioned separately as 'a common local name' $(A S D)$ or together with another item, e.g. Northampton. The consonant is also found with other place-name types ending in -ton. To identify such items, the Old English corpus was searched for place names containing an $m t$ cluster, which emerged due to the addition of the above-mentioned elements. This resulted in eight items: Hampton(shire), Northampton(shire), Southampton(shire), Wolverhampton, Bempton, Brampton, Compton and Rimpton. Additionally, place names with an $m s$ cluster were identified, 
the search yielding a further eight items: Berkhamsted, Cockampstead, Dunhampstead, Elmhamstede, ${ }^{5}$ Finchampstead, Hampstead, Peorhamstede and Stanhamstede. Although place names obviously do not provide as reliable evidence as common words, they are briefly discussed here for two reasons: first, to expand the data for $p$-epenthesis, which is quite scant in comparison to that illustrating the addition of $b$, and, second, to see whether the analysis of the process of $p$-epenthesis in place names would lead to the same observations as those for common items. Hence, I searched for the listed names in the corpora to identify their forms. I supplemented the data collected with the information from two dictionaries of place names, namely Ekwall's Concise Oxford Dictionary of English Place-Names (ODEPN) and Watts's Cambridge Dictionary of English Place-Names (CDEPN).

According to the data, the first place names affected by labial epenthesis were (chronologically) Compton, Wolverhampton, Brampton, Bempton, Hampton, Hampshire and Southampton(shire), all of which have appearances with $p$, albeit usually a single case, before the end of the twelfth century. Of those, the earliest attestation of the $p$-variant seems to be that of Comptone in Surrey recorded in 675 in Cartularium Saxonicum (ODEPN, CDEPN). The next to develop $p$ in written variants were Hampstead, Northampton and Finchampstead, which are found with the stop before the fifteenth century. Rimpton is not listed with $p$ in the dictionaries but the form occurs in the mid-seventeenth century in EEBO. As regards other items, they either have no entry in the dictionaries (Elmhamstede, Peorhamstead, Stanhampstead) or they always appear there (and in other data) without the stop (Cockhampstead, Dunhampstead $\left.^{6}\right)$. Interestingly, one item seems to be an exception since it has never been recorded with $p$, namely Berkhamsted. For the majority of names, both variants coexisted in the language, often for many centuries, as was the case with e.g. Hampton(shire) and Southampton(shire), whose $p$-less variants are attested even in the eighteenth century.

The data concerning place names thus suggest that items containing an $m t$ cluster were more prone to epenthesis than those with $m s$. This is shown by the fact that names with $m t$ are recorded with $p$ earlier and the data contain no exceptions to epenthesis, whereas among those with $m s$ there is Berkhamsted, which resisted epenthesis, and Medeshamstede, which had it only occasionally (see section 3.2 below).

\subsection{Occasional and temporary epenthesis}

As mentioned above, the forms which reveal epenthetic $p$ only occasionally and are now attested without it include cemette (PDE ant), antemn (PDE anthem), comte (PDE count, verb and nouns), column, dreamt, hymn, nemnan (PDE name), somnour (PDE summoner) and the place name Medeshamstede. Table 2 shows their first and last attestations with $p$.

\footnotetext{
5 Names which have not been identified as current nowadays are given in the form attested in the corpus.

${ }^{6}$ Dunhampstead is missing from CDEPN, which only records the form Dunhampton.
} 
Table 2. First and last occurrences of items with epenthetic $\mathrm{p}$ in the data

\begin{tabular}{llc}
\hline \hline & First record with $p$ & Last record with $p$ \\
\hline anthem (OE antefn) & OE & 1564 \\
hymn (OE (h)ymen) & $c .1225(? a .1200)$ & 1569 \\
name (OE nemnan) & $c .1230$ & 1782 \\
dreamt (ME dremed, drempte) & $a .1325(c .1250)$ & 1676 \\
summoner (ME somnour, sompnour) & $a .1325(c .1280)$ & 1958 \\
ant (OE ææmette) & 1382 & 1582 \\
count (ME count-, compt-) & $a .1393$ & 1861 \\
column (ME colompne) & $c .1450(a .1449)$ & 1577 \\
Medeshamstede (OE Medeshamsted) & 1668 & 1681 \\
\hline \hline
\end{tabular}

In table 2, the items affected are arranged according to their first attestation with epenthetic $p$. Note that the list of words discussed disregards items which were also affected by epenthesis but did not survive to Present-day English, such as e.g. amtman 'bailif', recorded also as amptman, or demster, with a variant dempster, an item obsolete in English and used only in Scots $(D S L)$. As can be seen, the majority of words appeared with the voiceless labial stop in the Middle English period, although antemn shows epenthesis already in Old English (e.g. in Benedict's Rule), while Medeshamstede only shows it in the seventeenth century (The Church-History of Brittany, 1668). The $p$-forms typically disappear in Early Modern English (sixteenthseventeenth centuries) with two words, nemnen and count, displaying variation till the second half of the eighteenth and the second half of the nineteenth century, respectively. According to the $O E D$, the word summoner still appeared with $p$ in the twentieth century, although only in historical contexts. This makes the word an item recorded with and without $p$ for the longest time, i.e. around six centuries.

In the words listed in table 2, epenthesis is observed in three contexts. Apart from the above-mentioned clusters $m t$ (cemette, comte, dreamt) and ms (Medeshamstede), the insertion of $p$ is also observed between nasals mn (antemn, column, hymn, nemnan and somnour), a context which is not observed in the case of permanent $p$-epenthesis in English. The items with an $m t$ cluster include two native words (cemette, dreamt) and one borrowing from French (comte). The earliest $p$-form recorded belongs to the past tense of dremen 'to dream'. The verb, unattested in Old English, is first recorded in Middle English, when it has two types of past forms, i.e. those with -ed (dremed) and those with - $t$ (dreamt). In the latter, the attachment of the suffix results in the labial nasal plus dental stop cluster, allowing the development of epenthetic $p$, resulting in dreampt(e). The data show that, in Middle English, whenever the past tense is created via the attachment of $t$, the epenthetic stop is always present. The form dreamt without $p$ is secondary, appearing only at the beginning of the seventeenth century. Although the $O E D$ gives 1628 as its first attestation, the data reveal earlier examples, as in (5). 
(5) (a) ... I dremt his bow was broke, and he was slaine... (1606, Bartlet, $A$ booke of ayres, song VI)

(b) ... I neuer dremt of any thing lesse the building churches, ... (1606, Peacham, The art of dravving vvith the pen ..., unnumbered)

Similarly, the date of the last usage of dreampte should be extended from 1653 (OED) to 1676, when the variant is used in News from the sessions house in the Old-Bayly London, which is included in EEBO.

The second word, ant, is affected by epenthesis in the second half of the fourteenth century, when the variant amptis is used in Wyclif's Bible, and continues in English till the second half of the sixteenth century. Around that time, the new variant ant, with the dental, rather than labial, nasal appears, which does not meet the context for epenthesis. Note, however, that the sequence ampt survives today in the place name Ampthill.

In contrast to the previous two cases, count is a borrowing from French, ultimately coming from Latin comptum, hence, its spelling 'was refashioned in 14th cent., after Latin, as compte' (OED, count). And indeed, the fourteenth century witnesses the appearance of $p$ in verbal forms (e.g. compteth, compten in Gower's Confessio Amantis) and nominal forms (e.g. compte in Chaucer's Romance of the Rose). The $p$-variant of this word is very persistent ${ }^{7}$ since compte is recorded even in the nineteenth century and that form is much more frequent than the one with an $m t$ cluster, which is typically used as a title (comte) and an element of place names (e.g. Franche-comte). As in the case of ant, the variant with epenthesis is replaced by the one with $n t$.

The sequence $m s$ was identified in only one word with non-permanent epenthesis, i.e. the place name Medeshamsted. In both Old and Middle English, the name is written only as the variant without $p$. The labial stop appears in Early Modern English, but it is very rare as EEBO records only three such uses as compared to 159 instances of Medeshamstead. This, however, is not that surprising since it is a historical name and as such it is preserved in its old form, often with the explanation that this place is 'now (called) Peterborough'.

The last group of words are those with an $m n$ cluster, identified in five items. The first of them to appear with $p$ is antemn 'anthem', which comes from Latin antefana and in Old English was typically used in the form antefn. Already in that period, however, its variant antemn emerged, with the cluster $m n$, which created a context for the epenthetic labial stop $p(O E D$, antemn $)$. The form antempn(e) is used till the mid-sixteenth century: the last quotation from the $O E D$ comes from 1530, but EEBO includes one instance from Rastell's $A$ confutation of a sermon printed in 1564 .

The next item with the $m n$ sequence with $p$ is hymn, an OE borrowing of Latin hymnus, mostly attested in the form $(h) y m e n$, which means that in inflection there must have been a

\footnotetext{
${ }^{7}$ It is possible that it was merely the spelling that was refashioned to represent etymology (e.g. items such as debt, $d o u b t$, etc.). However, in view of numerous other items with $p$ appearing in an $m t$ cluster, as well as the usage of $m$ (rather than $n$ ) in this variant, it seems likely that the labial was present also in pronunciation.
} 
cluster $m n$. Still, the first recorded use with $p$, shown in (6), does not belong to Old but rather Early Middle English (?c.1225 (?a.1200)).

(6) For swa is inhis ympne. (Ancrene Riwle, British Library, MS Cotton Cleopatra C.vi, 1. 124)

Interestingly, the DOEC reveals the form ympnus; it is not present in an OE text but in the Latin title of a psalm, Te decet ympnus deus in Syon, included in the Winteney Version of Benedict's Rule. This is a later version of the rule so it cannot be treated as an Old English text, but the citation shows that epenthesis affected the word also in medieval Latin. ${ }^{8}$ According to the $O E D$, the labial stop is found in hymn till 1513, but my data reveal more than 150 uses in EEBO so it did not disappear in the Middle English period. The last attestation in the data is from 1569, the year of publication of Diodorus's A righte noble and pleasant history ..., which contains the form hympnes. Sources dated to later years also contain the variant but only while quoting older texts.

The OE form nemnan 'to name' developed into ME nemnen. First attested in Ancrene Riwle (c.1230 (?a.1200)), the variant nempne becomes more frequent than nemne, outnumbering it both in the CMEPV (146 instances to 104) and EEBO (61 instances to 1 ), and is present in the language until at least 1782. Its decline is best demonstrated by the data from ECCO, which contains only three instances of nempne, all in Warton's The History of English Poetry in quotes from Lives of Saints 'written after the year 1169' (Warton 1774-81: 14), thus a historical text. The $p$-less form nemne is not found there at all, showing that name was already functioning as the main variant.

The last two items, summoner and column, are both borrowings. The former comes from French and was first recorded in English in c.1300. The word is found in Southern Passion preserved in MS Harley 2277, in the form somenours, which, curiously, appears as sompnours in MS Pepys 2344 from a.1325. Thus, the two variants are attested in English almost at the same time. They both continue to be used till modern times, with the forms sompner/sompour still found, albeit very rarely, in twentieth-century texts. The final item, column, entered English from Latin (columna/ columpna) via French (colompne/colombe) around 1440. The OED has only one attestation of the form with $p$, given here in (7), which suggests that it might have been a unique usage.

(7) In thyse grete colompnes or pylers..were grauen the vii scyences. (1481, Caxton's trans. Myrrour of Worlde iii. xi. 158)

However, as the data from the CMEPV and MED show, the form with $p$ was, in fact, predominant in Middle English. The corpus contains three tokens and the $M E D$ lists five quotations, with no instances of a $p$-less variant in either. Soon, the situation changes radically as shown by the data from EEBO with more than a thousand tokens without $p$ vs 24 of colompne/columpne, the most recent coming from 1577.

${ }^{8}$ Cf. e.g. the form ympnare quoted in Glossarium medice et infima latinitatis (Du Cange et al. 1883-7). 
In none of these words did labial stop epenthesis become permanent. In the two items with an $m t$ cluster (ant and count), $m$ was replaced by $n$ thus creating a homorganic cluster $n t$. In count, the replacement seems to have been quite natural, since for both words, i.e. the one denoting the title and that referring to calculation, the variants with $n t$ already existed in French before the words entered English (e.g. AF/CF conte(r)). Ant arose in the fifteenth century. Interestingly, the word also survived with the labial nasal as emmet, where the problematic cluster was avoided due to the preservation of the vowel. The words with an $m n$ cluster typically dropped the second nasal from the pronunciation (anthem, column, hymn), although in the case of nemnan one may speak of the elimination of the lexeme, since, according to both the $M E D$ and $O E D$, nemnan developed from $\mathrm{OE}$ (ge)nemnan while name derives from (ge)namian. Although cognates from a common source and with very similar sense, the latter eventually ousted the former. Summoner, like emmet, has a vowel separating the two sounds in question. This leaves only two words in Present-day English which still meet the context for epenthesis: Medeshamstead and dreamt. The former has quite rare attestations since it is only used in historical contexts. The latter is still quite often encountered, although its frequency is considerably lower than that of the regularized variant dreamed: in British English the ratio of the two forms is $27 \%$ : $73 \%$ (British National Corpus (BNC)), in American the variant dreamt is marginal with the ratio 11\% : 89\% (Corpus of Contemporary American English (COCA)).

\section{Epenthetic $b$}

As was observed in the case of $p, b$-epenthesis can also be either permanent or occasional/ temporary. The letter $b$ was permanently inserted in at least 17 items: bramble, crumb, ember, famble, fimble, fumble, limb, mumble, nimble, numb, rumble, shamble, slumber, stumble, thimble, tumble and thumb. The list is considerably longer than the one for $p$-epenthesis, indicating that the process was more common for the voiced stop. Occasional and temporary $b$-epenthesis is observed in several words, all of which are obsolete now, with one exception, i.e. hemlock.

\subsection{Permanent epenthesis}

Four words, fimble, rumble, stumble and tumble, display $b$ from their first attestation in English. The epenthesis here is observed only on comparing cognates from other languages and/or variants without the stop encountered in English.

Chronologically, the earliest of the four items is tumble, first attested in English in 1303 in the form tumbled, as in (8).

(8) Eroud swore / To here pat tumbled yn pe flore (Mannyng, Handling Sin, British Library, MS Harley 1701, 11. 2819-20)

The fact that $b$ is not original is shown by cognates such as German tummeln, Frisian tommelje, or Danish tumle $(O E D)$. Interestingly, this form gave rise to the verb tumbian 'to 
tumble, to dance' $(A S D)$ albeit used very rarely (two attestations plus three of the related noun tumbere 'a tumbler, a player'), in the Old English period. The verb re-emerges in the fourteenth century and its sense undergoes modification, presumably under the influence of the French verb tumber/tomber 'to fall'. According to the dictionaries, the first record without the stop is from Barbour's Bruce 1487 (a.1380), which contains the forms tumlilt and tummyll. The $b$-less variant appears for the last time in The flytting betwixt Montgomerie and Polwart from 1629 but, as the data from the corpora show (10 tokens in EEBO), its frequency was never high.

The pattern is repeated in the case of stumble and rumble. Both emerged in English with the epenthetic stop in the fourteenth century, as shown in (9), the former in 1303, the latter in c.1405 (c.1375).

(9) (a) Ful many on stumble vp and down (Mannyng, Handling Sin, British Library, MS Harley 1701, 1. 6521)

(b) The peple cride and rombled vp and doun (Chaucer, The Monk's Tale, National Library of Wales, MS Peniarth 392D (Hengwrt), 1. 449)

Later, both verbs are recorded without $b$, e.g. stomlep in Trevisa's translation of Bartholomaeus (a.1398) and rummuelon in Promptorium parvulorum (1440). Although the $O E D$ provides only two citations for the $b$-less forms of stumble, a verbal form from Torrent of Portyngale (a.1500 (a.?1400)) and an adjectival form from The Castle of Perseverance (c.1425), the data contain six more examples (plus one noun), the most recent coming from Fovrteen sermons dated to 1697. Note, however, that the stop is never missing from the noun stumble. As regards rumble, the variant without $b$ is very rare in the data, with merely six examples from EEBO (plus single uses of a noun), but, according to the $O E D$, it is still present in the language in Scottish English (also in Scots) and in northern Irish English in the sense 'to agitate, to shake'.

The last item in the group, fimble, is a borrowing from French ( femelle 'female hemp" ${ }^{\text {) }}$ but is also an obsolete variant of fumble and famble. Yet, as noted in the $O E D$, it is attested without the stop only as the former, since the quotation from ?1507 provided by the dictionary is the only recorded $b$-less form.

The extant literature lists one more item, which displays the emergent stop from its first record in English, namely timbrian 'to build'. However, in the case of this verb the fact that $b$ is not etymological is proved only by its reconstructed form *tim- $r$ - and cognates such as Dutch timmeren or Danish tömmre. Labial stop epenthesis is visible not only in English but also in some other Germanic languages, e.g. Old Saxon timbrian, Old High German zimberen, or Old Norse timbra $(O E D)$. Thus, since it is impossible to verify whether epenthesis took place in English or at an earlier stage, the item is not included in the analysis. In any case, in English, the word it is always attested with the stop.

9 The name was applied to the male plant, with carl hemp 'male' used for the female plant, the mistake long noticed and discussed by biologists (see $O E D$ ). 
Table 3. First occurrences of surviving words with epenthetic b

\begin{tabular}{lll}
\hline \hline & First record in English & \multicolumn{1}{c}{ First record with $b$} \\
\hline bramble & OE & $c .1000$ (Sax. Leechd.) \\
thumb & OE & 1137 (PetChr) \\
ember & OE & $a .1400$ (Lanfrank) (?) \\
thimble & OE & $c .1440$ (P.Parv.) \\
crumb & OE & $c .1450$ (Alphab) \\
shamble & OE & $1477-8$ (Comm) \\
nimble & OE & $a .1500$ (?c.1300) (Bevis) \\
limb & OE & 1595 (Caxton) \\
slumber & $c .1220$ & 1362 (PPl) \\
mumble & $c .1325$ & $c .1450$ (Alph.Tales) \\
famble & $a .1400$ & 1568 (Osório) \\
numb & $a .1400$ & 1572 (Huloet) \\
fumble & $? 1507$ & 1527 (Skelton) \\
\hline \hline
\end{tabular}

The remaining 13 items, listed in table 3, underwent $b$-epenthesis some time after their first attestation in English.

In contrast to table 1, presenting the results of Wełna's analysis, table 3 disregards the above-mentioned items which display epenthesis from their first attestation in English. On the other hand, the list is augmented with three recent words subject to epenthesis, i.e. famble, numb and fumble. As can be seen, epenthesis affected some words quite quickly, e.g. bramble and thumb appear with $b$ already at the end of the Old English period; while fumble is recorded with the stop about 20 years after its first attestation in English. In the case of other words, the process was much slower, the best example here being limb which, although used already in Old English, is first recorded with $b$ only at the end of the sixteenth century.

The analysis of my corpus material has led me to revise some of the dates for the first attestations suggested by Wełna on the basis of the dictionaries. In the $O E D$, the first usage of ember with $b$ is dated to Promptorium parvulorum from $c .1440$, but the form ember is found in Lanfrank's Science of cirurgie included in the CMEPV, dated to a.1400, given here in (10).

(10) ... bynde yt in a clothe \& put yt under embers, ... (Lanfrank's Science of cirurgie, Bodleian Library, MS Ashmole 1396, p.190)

This example, however, is not completely reliable since it does not come from the body of the text but is encountered in a marginal note. As explained by the editor: 'The translator has omitted the prescription of oleum tartarinum, given in the Lat. original. It is written by a later hand on the margin of lf. 114, bk.' Thus, it is impossible to suggest its exact dating.

For nimble, the earliest occurrence the OED provides is the 1496 version of Treat. Fishing, whereas nemble is encountered in The Romance of Sir Beues of Hamtoun, the original of which is dated to the beginning of the fourteenth century, given here in (11). 
(11) Syr Beuys was bothe nemble and wyght (The Romance of Sir Beues of Hamtoun, Chetham's Library MS 8009, 1. 2252)

But yet again, this dating is quite vague since the form is in the version preserved in Chetham's Library MS 8009, assigned to $a .1500$, thus it is unclear whether it belonged to the original text or was changed later and, if so, when exactly. The form numb is first recorded in $1610(O E D)$ but EEBO contains e.g. Huloets dictionarie newelye corrected from 1572, i.e. around forty years earlier, which includes the phrase 'Members being ded or numbe'. Additionally, the dating of the form limb, which Wełna assigns to the latter half of the sixteenth century, can be specified as 1595 , in the edition of Caxton's Blanchardyn and Eglantine, shown here in (12), from the CMEPV.

(12) ... who not only had bemangled his limbes, but alfo bereft him of his looue and Miftreffe, ... (Caxton's Blanchardyn and Eglantine, p. 22)

In the case of almost all items, the two types of forms, i.e. those without and those with epenthetic $b$, coexisted for some time in the language. As the timeline in figure 1 shows, the period of such coexistence may range from merely a few years to several centuries.

$11 \mathrm{c} \quad 12 \mathrm{c} \quad 13 \mathrm{c} \quad 14 \mathrm{c} \quad 15 \mathrm{c} \quad 16 \mathrm{c} \quad 17 \mathrm{c} \quad 18 \mathrm{c} \quad 19 \mathrm{c} \quad 20 \mathrm{c}$

bramble

thumb

ember

thimble

crumb

shamble

nimble

limb

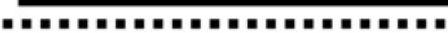
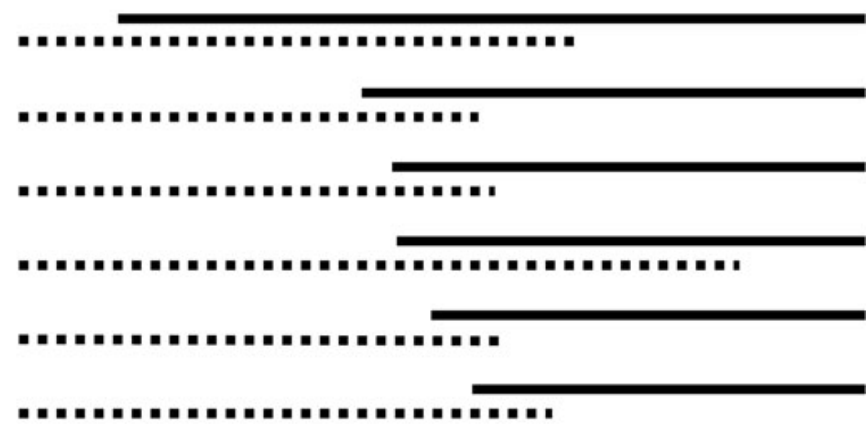

slumber

mumble

famble

numb

fumble

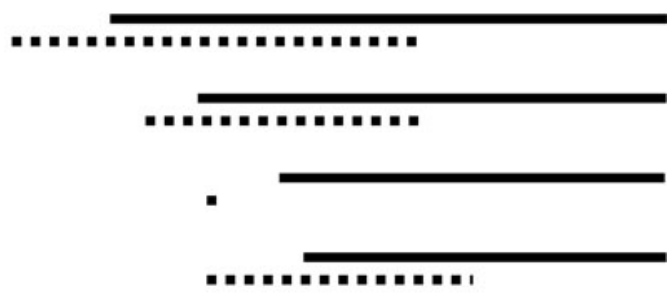

Figure 1. The occurrences of words with epenthetic $b$ (solid line) and without (dotted line) 
The longest coexistence of forms with and without $b$ is recorded for thumb, which first shows evidence of epenthesis in 1137 but the variant without the stop was in use until the end of the seventeenth century. Thus, the two types of forms were present in the language for around 500 years. The second longest time span belongs to bramble (around 415 years), followed by crumb (around 380 years). On the other hand, the data from the dictionaries and the corpora suggest that famble and fumble appeared with epenthetic $b$ only some time after the forms without the stop became obsolete, suggesting that they never coexisted as written variants.

The material examined here also enables post-datings for the last recorded uses of $b$-less forms provided by $O E D$. For shamble, the last record can be extended from 1574 (10th Rep. Royal Comm. Hist. Manuscripts) to 1593 (Fruitfull lessons, ...), that for nimble from 1568 (Satirical Poems Reformation) to 1607 (Lingua: or The combat of the tongue ...). Yet the biggest revisions in dating are for ember and slumber, which are attested in the corpora respectively 50 and 100 years later than the dates given by the $O E D$ : the dictionary quotes the last attestation of a $b$-less form of ember from a.1522 (Douglas's transl. of Aneid), but this type of variant is found in a text from 1579 (13a), while slumber, last recorded in the OED in 1599 (Hume's Hymnes) is attested in 1699 (13b).

(13) (a) ... and couer it in the hoat Emers of smale coales and ashes. (Bulleins bulwarke of defence ..., p. 3)

(b) She adds, she's troubled a nights with broken Slumrs (The characters, or, The manners of the age by Monsieur de la Bruyere ..., p. 259)

Note also, that some $b$-less variants (e.g. of shamble, nimble or numb) are encountered in particular dialects long after they became obsolete in standard English.

The words affected by $b$-epenthesis have different frequencies, thus the search for some of them in the corpora gives scant results. To these belong especially the words that appeared in the language or were affected by epenthesis most recently, such as fimble, fumble and numb, for which little or no comparative data can be found in the medieval English corpora. Also thimble and, quite surprisingly, ember, have only a few attestations in the corpora of texts earlier than Early Modern English (EEBO). In the case of such words, it is difficult to trace the changing ratio of forms without and with $b$. As regards other items, the data show that for bramble, thumb and slumber, the forms with $b$ outnumber those without the stop already in the CMEPV, the ratio being 15:1, 112:13 and 52:32, respectively. For the remaining words i.e. crumb, mumble, nimble and shamble, $b$-variants are still a minority in Middle English and become more frequent than the ones without $b$ only in EEBO.

As the examples show, $b$-epenthesis is encountered in three contexts: (1) between $m$ and $l$ (bramble, famble, fimble, fumble, mumble, nimble, rumble, shamble, stumble, thimble, tumble), between $m$ and $r$ (ember, slumber) and word-finally after $m$ (crumb, limb, numb, thumb). All these contexts have been discussed in linguistic literature (see section 2). Obviously, in some items, the context was met only when the word was inflected, since the form often contained an intervening vowel, e.g. OE brómel (PDE 
bramble), numel (PDE nimble), pýmel (PDE thimble), scomul (PDE shamble), and/or emerged when the vowel was lost. It is noteworthy that the words are typically much more frequently encountered in the forms demanding the vowel than in the ones without it, e.g. for brémel in the DOEC, there are 31 tokens of the form with the vowel (as yielded by a search for the string bróm $(b) e l^{*}$ ) vs 17 without it (from a search for the string bróm $\left.(b) l^{*}\right)$. And, curiously, in the case of bramle the emergent stop appears more often when $m$ and $l$ are separated by the vowel (3 tokens of brembel/ brember) than when the cluster is present ( 2 tokens: brembrum and bremblas). Also other items (numel, pýmel, scomul) are never attested in the corpus in the inflected forms containing an $\mathrm{ml}$ cluster. Thus, it seems that the elimination of an unstressed vowel was much more effective for epenthesis than the context created by inflection. As regards words with final epenthetic $b$, the addition of the stop is due to analogy to words with final $m b$, especially when $b$ was no longer pronounced, which led to the appearance of hypercorrective forms with $b$. In this case, it was undoubtedly only the letter that was added and not the sound.

\subsection{Occasional and temporary epenthesis}

As mentioned earlier, most words which showed an occasional or temporary variant with epenthetic $b$ did not survive in the language, e.g. OE abum 'son-in-law', cumul 'swelling', or simle 'a service, continual'. Thus, English has only one item that underwent such epenthesis for a period and survived until the present day, i.e. hemlock (OE hymlic). The first record of that noun with a labial stop is from the Old English period in LatinOld English Glossaries, which contain the form huymblicae (glossing Latin cicuta). This is also the only $b$-variant of the word in the period. Similarly, the Middle English corpora examined contain only one instance of that word, the form humbloks found in Mandeville's Travels. The noun gains frequency in later texts, as shown by around 1,200 attestations in EEBO, 28 of which have $b$. The last record of the $b$-form is dated to $1729(O E D)$.

In hemlock, the context for epenthesis is between $m$ and $l$. Thus, the environment for the occasional $b$-epenthesis is not different at the consonantal level from that for the permanent one. The word hemlock has a full vowel following, however, while items showing permanent epenthesis typically have a reduced one, although this difference is observed in one word only, other items (apum, cumul, simle) not showing such a context.

\section{Dialectal distribution}

As regards geographical distribution, the words with epenthetic $p$ attested as early as Old English (empty, anthem) appeared in the south-western areas: empty in Ælfric's texts, anthem in Benedict's Rule. The other items were recorded with $p$ for the first time in the East Midlands (ant, column, count, dream) or the West Midlands (hymn, nemnen). Throughout the Middle English period, the variants with labial stops were mostly used 
also in the Midlands, although some are attested in the northern (column, hymn, nemnen) and southern (anthem, empty, nemnen) areas.

Similarly, the forms which appeared with epenthetic $b$ earliest, i.e. bramble and thumb, were used in the South-West, the former in Ælfric's De initio creaturae, Leechdoms, Genesis and Latin-Old English Glossaries, and the latter in the Anglo-Saxon Chronicle (1137, Bodleian Library, MS. Laud Misc. 636). The $b$-forms which emerged in the Middle English period are recorded in the East Midland area. Yet, even if they developed there, the variants quickly appeared also in other dialects, since during the period, the $b$-forms are encountered not only in the Midlands but also in the southern (e.g. thumb) and northern areas (e.g. bramble and tumble). Thus, the available written evidence suggests that the initiators of the process of labial epenthesis may have been in the central and eastern parts of England. It needs to be remembered, however, that the epenthesis is indubitably a spoken rather than written phenomenon and that the dialects are not all fully and equally represented with textual evidence, hence the above statement is merely an observation based on the material that survives, and could be examined.

\section{Exceptions to epenthesis?}

In order to identify potential exceptions to labial stop epenthesis, the Old English corpus was searched for items containing the most commonly attested contexts for the process. Thus, for $p$-epenthesis, an $m t$ cluster was looked for. The search yielded 13 items: beámtelg, emtwa, emtryming, frumtalu, frumteam, frumtihtle, hearmtan, Maerchamtune, (ge)rimtoel, palmtwig(ed), palmtreow, scemtinges and sealmtraht. As can be seen, in the majority of the words, the cluster emerged as a result of compounding with the element beam 'tree', frum 'first', hearm 'harm', palm 'palm', rim 'number' and sealm 'psalm'. In the remaining forms, the context was the result of prefixation of em- and sam-. As the data examined show, a morpheme or word boundary did not serve as an obstacle in the case of place names with -hampton and -ton, but it seems that in other cases such context did not favour epenthesis. Note also that most words that could be treated as exceptions did not survive beyond the Old English period, while from the two surviving ones palm tree started to be spelt separately thus splitting the relevant cluster, while the place name is now Marchington, so it is not meeting the context. The items containing an $m s$ cluster in Old English are also mostly compounds (e.g. with frum or ham) and they are usually obsolete or the cluster is created from the suffixation of an inflection such as $-s$ or $-s t$ (e.g. wyrms or demst). Note that nowadays the cluster is still found mostly in the word-final position in the plural. In this context, as well as in many words where $m s$ is encountered medially (flimsy, damsel, crimson) the fricative is voiced, and the epenthesis does not seem to occur in the context of $/ \mathrm{mz} /$. This leaves presumably only a few items in PDE, in some of which $p$ is noted in pronunciation, e.g. names such as Samson and Thomson.

A similar procedure was carried out in the case of $b$-epenthesis for an $m l$ cluster, which led to the identification of 11 lexemes: Bromley, cumlipe, cumlipnysse, cumlipian, 
cumliplic, dreamleas, dreamlic, hearmlēop, hearmlic, hearmloca and sealml(e)of. Yet again, the items identified are compounds, formed with cuma 'comer', hearm 'harm' and sealm 'psalm', as well as by the addition of the suffixes -lic and -leas. Also, as the data show, $b$-epenthesis did not affect compounds and was never attested in the context of suffixes such as PDE -ly and -less, the attachment of which creates the desired context even nowadays.

Thus, a brief analysis shows that it is difficult to talk about exceptions to labial stop epenthesis and it seems more logical to limit its application to non-derived contexts with the exception of the above-mentioned place names developing epenthetic $p$.

\section{Reasons for epenthesis}

Having presented the material, I now return to the question of potential reasons for labial stop epenthesis. As mentioned in section 2 , the process has been typically explained either in terms of syllable structure or the timing of articulatory gestures.

In the former approach, the addition of a stop is argued to improve the syllabic structure of the word affected. Items that underwent $p$-epenthesis originally contained a syllable ending in a labial nasal $m$, which was followed by one beginning with the dental stop $t$, e.g. OE am.tig or Ham.toun. After the addition of $p$, they were resyllabified as cemp.tig and Hamp.toun, respectively. Hence, the epenthesis resulted in 'syllables with more coda consonants than the underlying form has' (Warner 2002: 5), making the syllabic structure of the word more marked. This is a rather unwelcome result in terms of models such as Optimality Theory. The addition of the stop also fails to improve the Syllable Contact, which 'favors a sonority fall across syllable boundaries' (Czaplicki 2010: 182), since $p$-epenthesis changes syllable contact from a more preferred SC-1 (nasal+obstruent) to $\mathrm{SC}$ (obstruent + obstruent). In the case of epenthetic $b$, most words affected used to have an open syllable followed by one with the initial $m$, e.g. OE bra.mel or py.mel. The application of epenthesis moved the nasal to the preceding syllable, thus making the first syllable closed and putting the stop in the onset of the following one, e.g. bram.bel or bym.bel. This seems a plausible explanation, but one needs to remember that forms such as bramel or bymel did not meet the context for epenthesis in the first place. Rather, as explained above, the context arose only in inflection, or once the unstressed vowel was eliminated. Thus, the input is $\operatorname{braml}(e)$ and byml(e). If so, it cannot be claimed that epenthesis filled in 'empty first-syllable codas' (Minkova 2014: 48), because, since the sequences $m l$ and $m r$ are forbidden in English in onsets, the nasal $m$ must have already been in the coda before epenthesis. Hence, the addition of the stop affects only the syllable following the labial nasal in which it creates a complex onset, e.g. $\operatorname{bram} . b l(e)$ and $\operatorname{pym} . b l(e)$. Note, however, that once the final vowel is lost and the liquid becomes the nucleus, the stop creates an onset for the syllable that would otherwise consist of a nucleus only but this happens long after the epenthesis and cannot be regarded as its cause. And although the addition of $b$ could be seen as the improvement of Syllable Contact (from nasal+liquid to 
nasal+obstruent), this explanation lacks general application since it does not refer to the epenthesis of the voiceless $p$.

Incidentally, even if a syllable-based analysis does not account for epenthesis, it may at least explain its absence in some items. Numerous variants with epenthetic $p$, e.g. antempne, ampte, compte, drempte or columpne, once the final vowel was dropped, contained complex codas with sequences mpn or $m p t$, which violate the Sonority Sequencing Principle and are prohibited in English, and this was possibly the reason why epenthetic stops in such words did not prevail.

It thus seems that the reasons for epenthesis should be searched for in articulation. It is well known that the production of a nasal+liquid/stop sequence demands a swift movement of the velum, which needs to close the nasal cavity once the nasal is pronounced. If the velum closes before the release of the oral closure for the nasal, that release will result in the production of a stop that agrees with the nasal in the place of articulation, i.e. $p$ or $b$ after $m$. A slightly different articulation-based explanation can be offered for sequences $m n$, which are also a context for epenthesis. Ohala (1997: 89) assumes that the coarticulation of $m$ and $n$ traps some air between their places of articulation, which, when the oral cavity opens, is released producing 'a click-like "pop"", which listeners would interpret as "the only other acoustically similar sound that they are familiar with', namely $p$. In fact, Ohala claims that an epenthetic stop should not be called epenthetic or intrusive because there is no new element added to the word: the stop 'develops out of the rearrangement of pre-existing elements' (1997: 84) so it should be called 'emergent'. Obviously, in the articulatory approach, the stop is inserted regardless of its effect on the syllable structure (which is especially convincing in the case of dental stop insertion in words such as spindle, where the stop cannot be syllabified into the onset but rather becomes part of the coda of the preceding syllable, as confirmed by Lutz's (1985) data). And if the listeners assume that the stop they hear is an intentional element in a given word, its presence may become possible also in spelling.

\section{Conclusion}

The search for forms potentially affected by labial stop epenthesis revealed two items (plus 13 place names) that show permanent $p$-insertion and 17 words which developed $b$. Of those, some words possessed the stop already when they entered English. Additionally, there are 10 existent words which have appeared with the labial stops only occasionally and temporarily, 9 with $p$ and one with $b$, showing that epenthesis was not always lasting. Interestingly, the relation between items affected by permanent and temporary epenthesis in the case of the two labial stops is reversed, as it is 2:17 for $p$ and 9:1 for $b$.

The identification of forms with and without the labial stops in the historical corpora not only led to the establishment of the frequency of both types of forms but also allows pre-dating and post-dating for some attestations from the $O E D$, which could be changed in the case of numerous items. The most considerable difference in dating was 
observed for slumber, whose last use without $b$ is dated in the $O E D$ to 1599 but was found in our material a hundred years later, and ember, whose most recent $b$-less variant is dated in the $O E D$ to $a .1522$ but such a form was identified in a 1579 publication.

The data considered here suggest that epenthetic labial stops typically appeared first in the Midlands, although this might be simply due to the fact that the bulk of medieval material is located to that region, especially for the early years of the period. Later, the occurrences of forms with $p / b$ are also noted in the South and North. Thus, it seems that the process cannot be treated as limited to any area, but was rather independent of dialects.

The examination of contexts for epenthesis and the results of the process lead to the conclusion that labial stop insertion is perhaps best explained in terms of articulatory gestures, since the addition of the stop often makes the syllable structure more complex and marked than it used to be before the stop appeared.

Author's address:

Department of the English Language and Linguistics

Institute of English Studies

University of Warsaw

ul. Hoża 69 00-681 Warsaw

Poland

a.wojtys@uw.edu.pl

\section{References}

$A S D=$ Bosworth, Joseph \& T. Northcote Toller. 1898. An Anglo-Saxon dictionary. Digital edition available at www.bosworthtoller.com

$\mathrm{BNC}=$ British National Corpus. www.english-corpora.org/bnc/

$C D E P N=$ Watts, Victor. 2007. The Cambridge dictionary of English place-names: Based on the collections of the English Place-Name Society. Cambridge: Cambridge University Press.

CMEPV = McSparran, Frances. 2010-. The Corpus of Middle English Prose and Verse. http://ets. umdl.umich.edu/m/mec/. Ann Arbor: Humanities Text Initiative - University of Michigan.

COCA $=$ Corpus of Contemporary American English . www.english-corpora.org/coca/

Czaplicki, Bartlomiej. 2010. Emergent stops in English and in Polish: Against a syllable-based accounts. Poznań Studies in Contemporary Linguistics 46(2), 177-91.

$D O E=$ diPaolo Healey, Antonette, Dorothy Haines, Joan Holland, David McDougall \& Ian McDougall (eds.). The dictionary of Old English: $A$ to $G$, with an electronic version for Windows developed by Xin Xiang. Toronto: Dictionary of Old English Project 2008, on CD-ROM.

DOEC $=$ diPaolo Healey, Antonette, Joan Holland, Ian McDougall \& Peter Mielke. 2000. The Dictionary of Old English Corpus in Electronic Form. Toronto: DOE Project 2000.

$D S L=$ Dictionary of the Scots language. https://dsl.ac.uk/about-dsl/

Du Cange, Charles du Fresne et al. 1883-7. Glossarium medice et infimce latinitatis. Niort: L. Favre.

$\mathrm{EEBO}=$ Early English Books Online: Text Creation Partnership. University of Michigan Library. Available online at https:/quod.lib.umich.edu/e/eebogroup/ 
ECCO = Eighteenth Century Collections Online: Text Creation Partnership. University of Michigan Library. Available online at https://quod.lib.umich.edu/e/ecco/

Hock, Hans Henrich \& Brian D. Joseph. 1996. Language history, language change and language relationship: An introduction to historical and comparative linguistics. Berlin and New York: Mouton de Gruyter.

Hogg, Richard. 1992. A grammar of Old English, vol. 1: Phonology. Oxford: Blackwell.

Jakobson, Roman. 1929/1962. Remarqes sur l'évolution phonologique du russe comparée à celle des autres langues slaves. Travaux du Cercle Linguistique de Prague 2 [Reprinted in 1962 in Selected writings, vol. I: Phonological studies, 7-116. The Hague: Mouton.]

LAEME $=$ A Linguistic Atlas of Early Middle English, 1150-1325. 2008-. Compiled by Margaret Laing. www.lel.ed.ac.uk/ihd/laeme2/laeme2.html. Edinburgh: The University of Edinburgh.

Luick, Karl. 1940. Historische Grammatik der englischen Sprache, vol. 2. Leipzig: Tauchnitz.

Lutz, Angelika. 1985. Die Worttrennung am Zeilenende in altenglischen Handschriften: Phonologische Betrachtungen zu Claus-Dieter Wetzels gleichnamigen Buch. Indogermanische Forschungen 90, 227-38.

$M E D=$ Middle English dictionary. Ed. Robert E. Lewis et al. Ann Arbor: University of Michigan Press, 1952-2001. Online edition in Middle English Compendium. Ed. Frances McSparran et al. Ann Arbor: University of Michigan Library, 2000-18. http:/quod.lib.umich.edu/m/middleenglish-dictionary/

Mincoff, Marco. 1972. English historical grammar. Sofia: Naouka i Izkoustvo.

Minkova, Donka. 2014. A historical phonology of English. Edinburgh: Edinburgh University Press.

$O D E P N=$ Ekwall, Eilert. 1960. The concise Oxford dictionary of English place-names, 4th edition. Oxford: Oxford University Press.

OED $=$ Oxford English Dictionary. www.oed.com

Ohala, John J. 1997. Emergent stops: Diachronic and phonetic data. Proceedings of Seoul International Conference on Linguistics, 84-91. Seoul: Linguistic Society of Korea.

Payne, David L. 1981. The phonology and morphology of Axininca Campa. Arlington, TX: Summer Institute of Linguistics and University of Texas.

Prince, Alan \& Paul Smolensky. 2004. Optimality Theory: Constraint interaction in generative grammar. Oxford: Basil Blackwell.

Warner, Natasha. 2002. The phonology of epenthetic stops: Implications for the phoneticsphonology interface in Optimality Theory. Linguistics 40(377), 1-27.

Warton, Thomas. 1774-81. The history of English poetry: From the close of the eleventh to the commencement of the eighteenth century. London: J. Dodsley.

Wełna, Jerzy. 1978. A diachronic grammar of English. Part one: Phonology. Warsaw: PWN.

Wełna, Jerzy. 2005. 'Now you see it now you don't', or the fates of the Middle English voiced labial stops in homorganic clusters. In Nikolaus Ritt \& Herbert Schendl (eds.), Rethinking Middle English: Linguistic and literary approaches, 317-27. Frankfurt am Main: Peter Lang. 